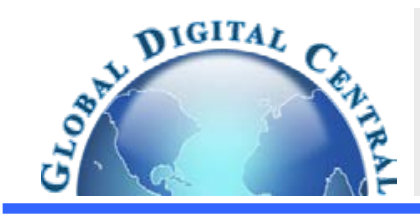

Frontiers in Heat and Mass Transfer

\title{
INFLUENCE OF RING SIZE AND LOCATION ON FLOW TOPOLOGY, HEAT TRANSFER STRUCTURE AND THERMAL EFFICIENCY IN HEAT EXCHANGER SQUARE CHANNEL PLACED WITH 30-DEGREE INCLINED SQUARE RING
}

\author{
Amnart Boonloi ${ }^{\mathrm{a}}$ and Withada Jedsadaratanachai ${ }^{\mathrm{b}, *}$ \\ ${ }^{a}$ Department of Mechanical Engineering Technology, College of Industrial Technology, King Mongkut's University of Technology North Bangkok, \\ Bangkok 10800, Thailand \\ ${ }^{b}$ Department of Mechanical Engineering, Faculty of Engineering, King Mongkut's Institute of Technology Ladkrabang, Bangkok 10520, Thailand
}

\begin{abstract}
This paper presents the numerical investigations (finite volume method with SIMPLE algorithm) on flow structure, heat transfer behavior and performance assessment in heat exchanger square channel placed with $30^{\circ}$ inclined square ring (ISR). The influences of ring size and placement on flow and heat transfer characteristics are considered for laminar flow region with the Reynolds number in the range around $100-2000$. The purpose for the insertion of the ISR in the square channel is to induce the vortex flow and also increase the turbulent mixing. The numerical result reveals that the ring size and location have effects for the changes of the flow and heat transfer behaviors in the tested section. The present of the ISR in the tested section gives the maximum heat transfer rate around 8.13 times above the smooth square channel. In addition, the optimum thermal performance at similar pumping power or TEF is around 3.10 .
\end{abstract}

Keywords: square ring; heat transfer; thermal performance; numerical study; Nusselt number.

\section{INTRODUCTION}

The designs of the vortex generators have been developed by many researchers. Propose for the development is to increase the heat transfer rate and thermal performance. The installation method, production and maintenance of the vortex generator are also important factors that must be considered. The type, size, thickness, height, placement, etc., of the vortex generators in the heat exchanger have effects on flow and heat transfer. Many researchers investigated the heat transfer, pressure loss and thermal efficiency in various types of the heat exchanger installed with vortex generators such as baffle (Arani and Moradi (2019), Naqvi et al. (2019), Ameur (2019), Saravanakumar and Kumar (2019)), rib (Bahiraei et al. (2019), Bai et al. (2019), Liu et al. (2019), Li et al. (2019)), winglet (Zhai et al. (2019), Awais and Bhuiyan (2019), Dezan et al. (2019)), etc. They reported that the vortex generators can improve the heat transfer rate and thermal performance in the heat exchanger.

The investigation for the development of the vortex generator in the heat exchanger can be separated into 2 ways; numerical and experimental investigations. The experimental result has higher reliability than the numerical result. However, it must spend high cost and resource for the experimental study. The numerical investigation can save cost and resource for the study process and also describe the mechanisms in the system. The understanding on flow and heat transfer mechanisms in the tested section is an important factor for the developments of the heat exchanger and vortex generators.

In the present research, the numerical prediction is selected to study the mechanisms in the heat exchanger square channel inserted with the vortex generators. The square ring (likes baffle or thin rib) is designed to improve heat transfer rate and thermal efficiency in the heat exchanger.
The inclined configuration is applied for the square ring to reduce the pressure loss in the tested section when compared with the general structure of the ring $\left(90^{\circ}\right.$ ring). The influences of the size and position for the inclined square ring in the heat exchanger on flow topology and heat transfer behavior are investigated. The laminar flow regime with the Reynolds number around $100-2000$ is measured for the present work. The numerical results are presented in terms of flow and heat transfer structures in the tested section. The thermal efficiency in forms of Nusselt number, friction factor and thermal enhancement factor is also summarized.

\section{HEAT EXCHANGER SQUARE CHANNEL PLACED WITH INCLINED ORIFICE}

The test section is a heat exchanger square channel placed with $30^{\circ}$ inclined square ring (ISR) as Fig. 1. The ratio between the ISR height (b) and channel height $(\mathrm{H}), \mathrm{b} / \mathrm{H}$, is called blockage ratio (BR). The blockage ratio is varied in the range $0.05-0.30$. The space between the outer edges of the ISR and the channel walls represents with "s", while $\mathrm{s} / \mathrm{H}$ is varied in the range $0-0.30$. The laminar flow regime with the Reynolds number around $100-2000$ (inlet condition) is considered for the current work. The pitch spacing ratio or $\mathrm{P} / \mathrm{H}$ and flow attack angle of the ISR are fixed for all investigated cases around 1 and $30^{\circ}$, respectively.

\section{ASSUMPTION, BOUNDARY CONDITION AND MATHEMATICAL FOUNDATION}

The assumption and boundary condition for the present investigation can be concluded as follows: 
o The fluid flow is counted in the laminar flow regime with the Reynolds number around 100 - 2000 (considered at the inlet of the channel).

o The convective heat transfer is considered, but the natural convection and radiation heat transfer are ignored.
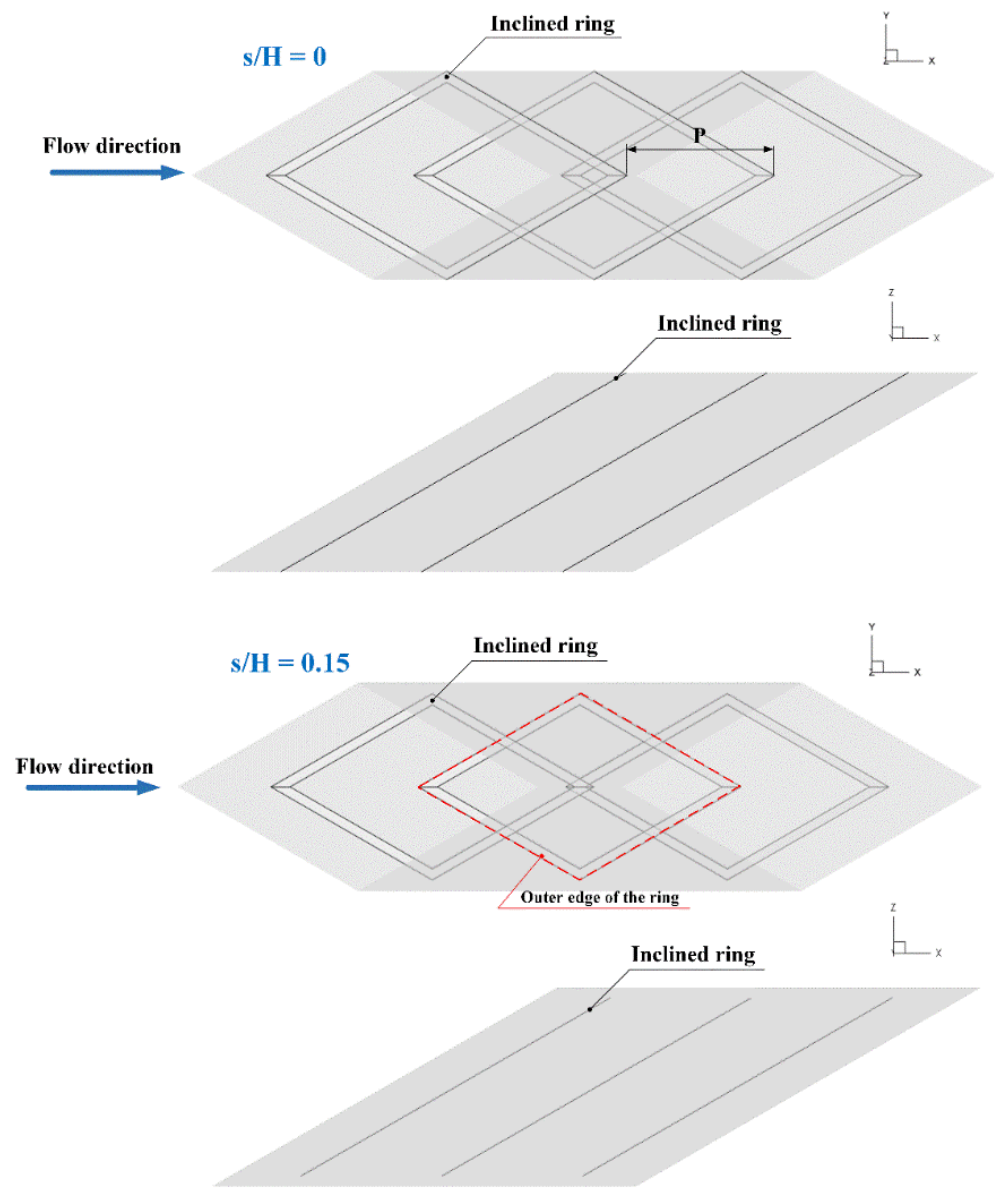

o The body force and viscous dissipation are disregarded.

o The flow and heat transfer are steady in three dimensions. o Incompressible condition is applied for the fluid flow.
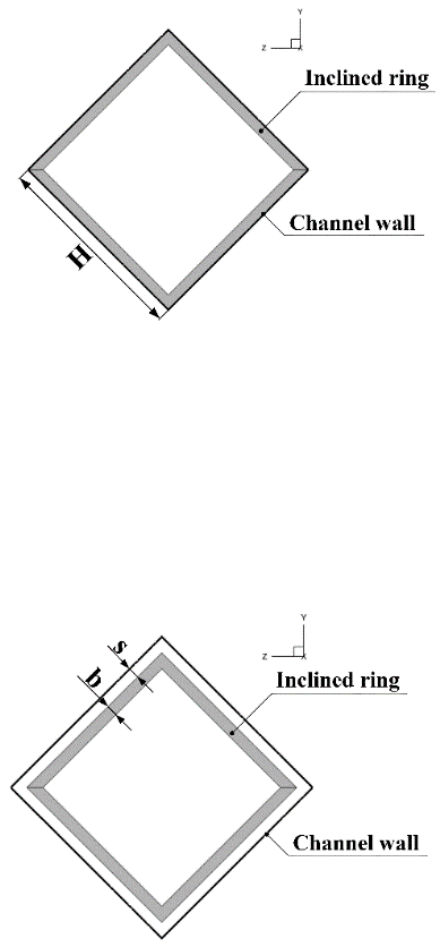

Fig. 1 Computational domain of the heat exchanger square channel equipped with ISR.

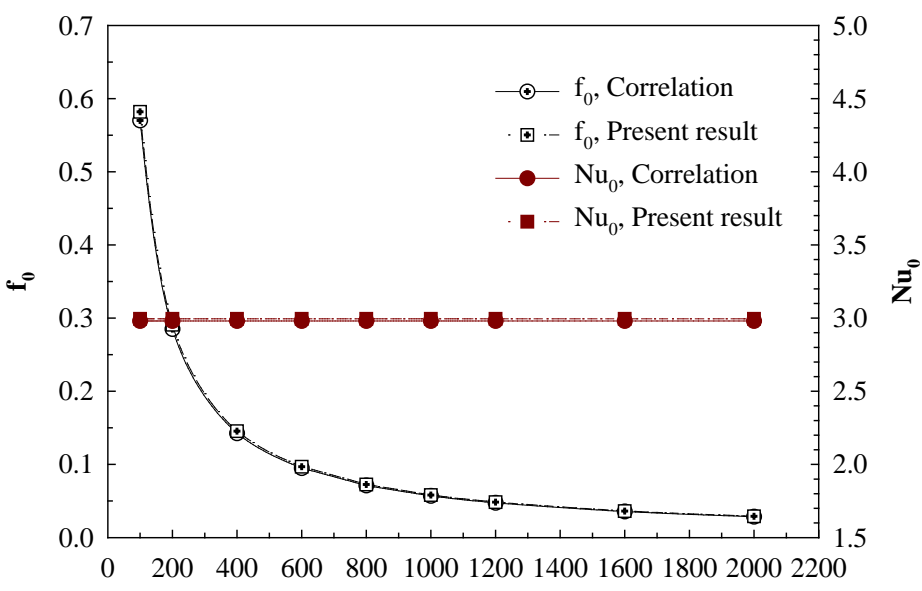

Re

Fig. 2 Verification of the smooth channel.

o No slip condition is applied for all sides of the channel walls and inclined rings.

o The test fluid is air with the temperature around $300 \mathrm{~K}(\mathrm{Pr}=0.707)$. The thermal properties of the air are assumed to be constant at the average bulk mean temperature (between wall and inlet).

o The constant temperature around $310 \mathrm{~K}$ is applied for the channel walls, while the inclined ring is assumed to be an insulator. o The periodic condition (Patankar et al. (1998)) is adopted for the inlet and outlet of the physical domain

The numerical problem is solved by finite volume method (SIMPLE algorithm). The tested section is governed by the continuity, the NavierStokes equations and the energy equation as equations 1, 2 and 3, respectively.

Continuity equation: 


$$
\frac{\partial}{\partial x_{i}}\left(\rho u_{i}\right)=0
$$

Momentum equation:

$$
\frac{\partial\left(\rho u_{i} u_{j}\right)}{\partial x_{j}}=-\frac{\partial p}{\partial x_{i}}+\frac{\partial}{\partial x_{j}}\left[\mu\left(\frac{\partial u_{i}}{\partial x_{j}}+\frac{\partial u_{j}}{\partial x_{i}}\right)\right]
$$

Energy equation:

$$
\frac{\partial}{\partial x_{i}}\left(\rho u_{i} T\right)=\frac{\partial}{\partial x_{j}}\left(\Gamma \frac{\partial T}{\partial x_{j}}\right)
$$

where, $\Gamma$ is the thermal diffusivity and is printed as follows:

$$
\Gamma=\frac{\mu}{\operatorname{Pr}}
$$

The continuity and momentum equations are discretized by the power law scheme, while the energy equation is discretized by QUICK scheme. The solutions are determined to be converged when the normalized residual values are less than $10^{-5}$ for all variables, but less than $10^{-9}$ only for the energy equation.

The air velocity is presented in term of the Reynolds number as equation 5 . The pressure drop of the tested channel is reported with the friction factor as equation 6 , while the heat transfer rate is presented with the local Nusselt number and average Nusselt number as equations 7 and 8 , respectively. The efficiency of the heat exchanger channel equipped with ISR is presented in form of thermal enhancement factor as equation 9.

$$
R e=\frac{\rho \bar{u} D_{h}}{\mu}
$$

$\mathrm{D}_{\mathrm{h}}$ is hydraulic diameter of the square channel heat exchanger.

$$
\begin{aligned}
& f=\frac{(\Delta P / L) D_{h}}{\frac{1}{2} \rho u^{-2}} \\
& N u_{x}=\frac{h_{x} D_{h}}{k}
\end{aligned}
$$

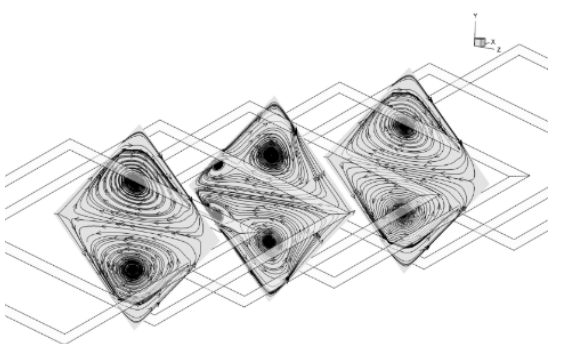

(a)

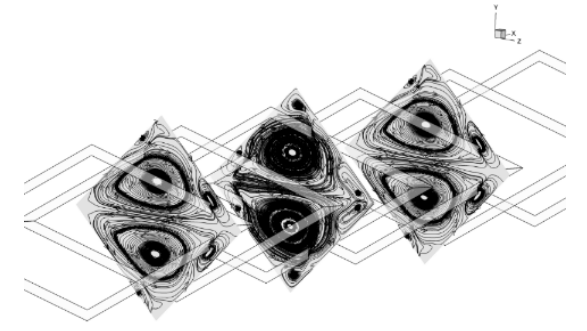

(c)

$$
N u=\frac{1}{L} \int N u_{x} \partial x
$$

The thermal enhancement factor (TEF) is defined as the ratio of the heat transfer coefficient of an augmented surface, h, to that of a smooth surface, $\mathrm{h}_{0}$, at similar pumping power.

$T E F=\left.\frac{h}{h_{0}}\right|_{p p}=\left.\frac{N u}{N u_{0}}\right|_{p p}=\left(N u / N u_{0}\right) /\left(f / f_{0}\right)^{1 / 3}$

The Nuo and $f_{0}$ are the Nusselt number and friction factor for the smooth square channel, respectively.

\section{NUMERICAL VALIDATION}

The numerical validation is an important part for the numerical investigation. It must sure that the creation domain can predict flow and heat transfer configurations in the tested section with high accuracy result. Therefore, the computational domain of the square channel inserted with ISR is validated. The validations for the computational domain in the laminar regime can be separated into 2 sections; smooth channel validation and grid independence.

The comparison between the present results (smooth square channel with no ISR) and the correlation values (Cengel and Ghajar (2015)) on both Nusselt number and friction factor is done. The deviations of the Nusselt number and friction factor are around $\pm 0.5 \%$ and $\pm 2 \%$, respectively. The validation of the smooth square channel can accept due to the deviations are not more than $\pm 5 \%$. The verification of the smooth square channel with no ISR is plotted as Fig. 2.

The grid independence check for the computational domain of the heat exchanger square channel inserted with ISR $(B R=s / H=0.15)$ is done by compared four models with difference grid numbers; 120000 , 280000, 360000 and 420000. The numerical result shows that the grid cell in the range around 120000 - 420000 gives similar Nusselt number and friction factor values. Therefore, the grid cell around 120000 is applied for all studied cases.

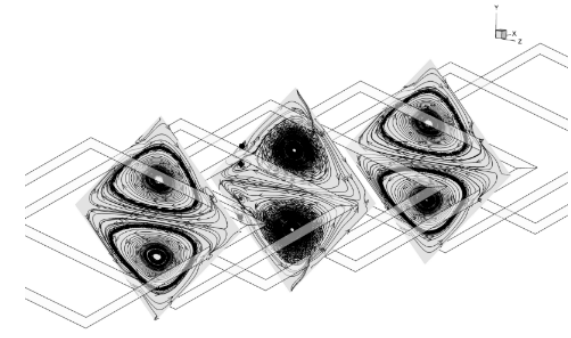

(b)

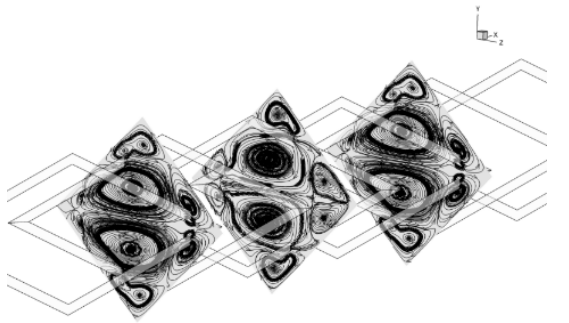

(d)

Fig. 3 Streamlines in transverse planes of the heat exchanger square channel equipped with ISR for (a) $\mathrm{s} / \mathrm{H}=0$, (b) $\mathrm{s} / \mathrm{H}=0.10$, (c) $\mathrm{s} / \mathrm{H}=0.20$ and (d) $\mathrm{s} / \mathrm{H}=0.30$ at $\mathrm{BR}=0.15$ and $\mathrm{Re}=1000$. 


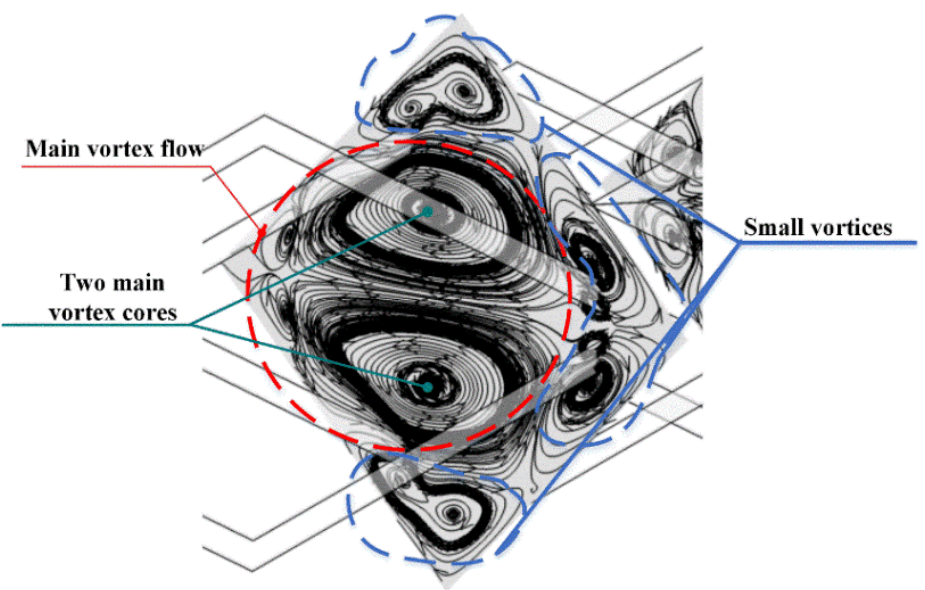

Fig. 4 Description of the flow mechanism.

\section{NUMERICAL RESULT}

Numerical results; flow and heat transfer, performance evaluation, for the heat exchanger square channel inserted with ISR are reported in this part. The mechanisms in the tested channel are presented in terms of streamlines in transverse planes, temperature distributions, local Nusselt number distributions, while the performance analysis is concluded in terms of Nusselt number ratio $\left(\mathrm{Nu} / \mathrm{Nu}_{0}\right)$, friction factor ratio $\left(\mathrm{f} / \mathrm{f}_{0}\right)$ and thermal enhancement factor (TEF).

\subsection{Flow structure and heat transfer}

Figs. 3a, b, c and d depict the streamlines in transverse planes for the heat exchanger square channel inserted with $30^{\circ}$ ISR at $\mathrm{s} / \mathrm{H}=0,0.10,0.20$

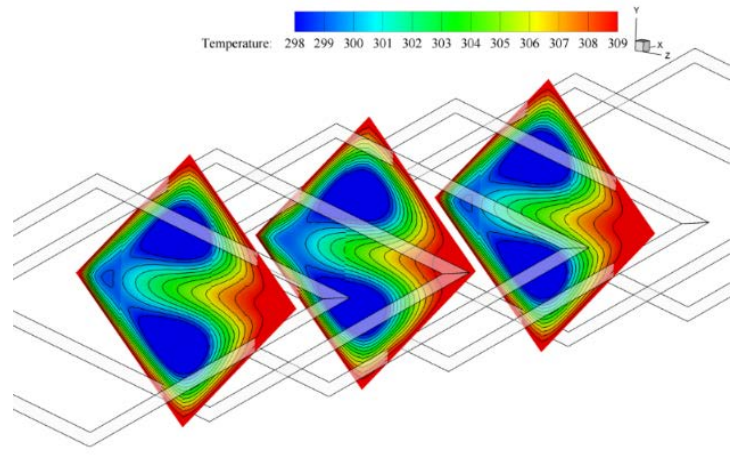

(a)

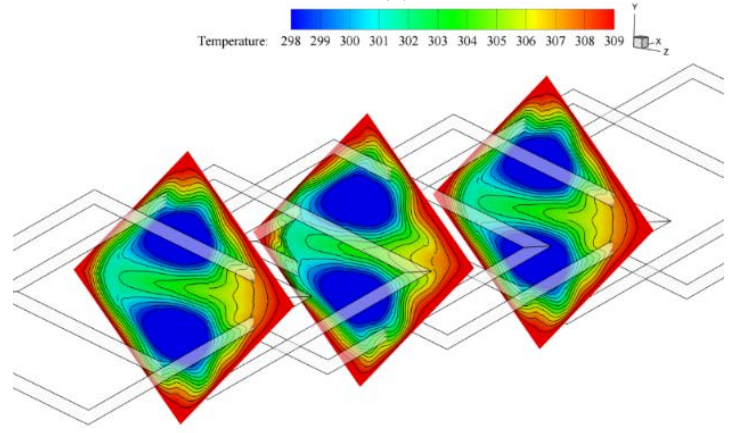

(c) and 0.30 , respectively, of $\mathrm{BR}=0.15$ and $\mathrm{Re}=1000$. Generally, the insertion of the ISR in the studied section can induce the vortex flow through the tested section in all cases. The vortex flow is a key for the enhancements of heat transfer rate and thermal performance. The vortex flow will disturb the thermal boundary layer on the heat transfer surface and also increase the turbulent mixing of the fluid flow. The turbulent flow pattern is found although the Reynolds number at the inlet is set as the laminar flow. For $\mathrm{s} / \mathrm{H}=0$ and 0.10 , the two main vortex cores are found at the upper-lower parts of each plane. For $\mathrm{s} / \mathrm{H}>0.10$, the small vortices near the channel wall are found. The small vortices may enhance the level of the turbulent fluid mixing or decrease the main vortex strength. The description of the flow mechanism in the heating section is depicted as Fig. 4.

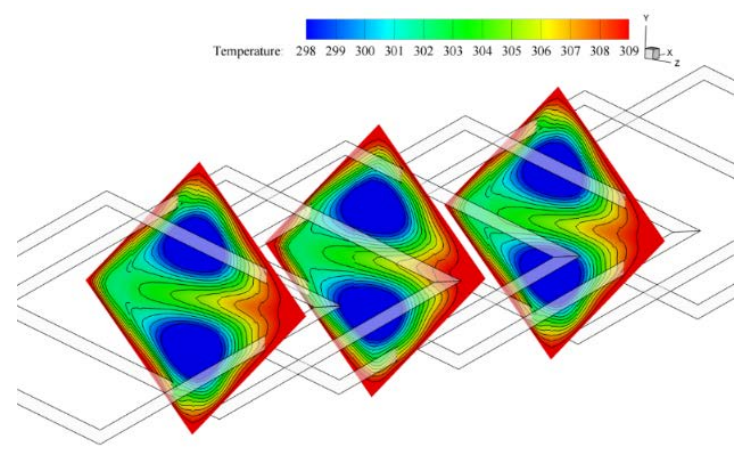

(b)

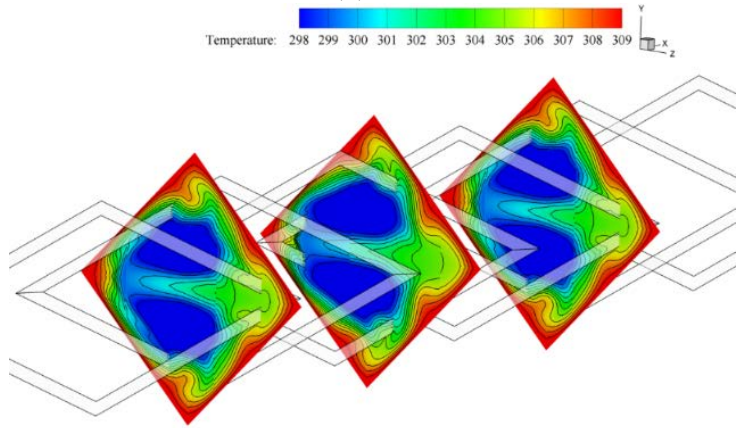

(d)

Fig. 5 Temperature distributions in transverse planes of the heat exchanger square channel equipped with ISR for $(\mathrm{a}) \mathrm{s} / \mathrm{H}=0$, (b) $\mathrm{s} / \mathrm{H}=0.10$, (c) $\mathrm{s} / \mathrm{H}=0.20$ and (d) $\mathrm{s} / \mathrm{H}=0.30$ at $\mathrm{BR}=0.15$ and $\mathrm{Re}=1000$.

The temperature distributions in transverse planes in heat exchanger square channel inserted with ISR are plotted as Figs. 5a, b, c and d, respectively, for $\mathrm{s} / \mathrm{H}=0,0.10,0.20$ and 0.30 at $\mathrm{BR}=0.15$ and $\mathrm{Re}=1000$. The temperature distribution in transverse planes is an indicator to check the change of the thermal boundary layer on the square channel walls. In general, the blue contour (cold fluid) is found at the center of the channel, while the red contour (hot fluid) is detected near the channel walls for the smooth channel with no ISR. The installation of the ISR in the tested 
channel can change the heat transfer behavior. The change of the thermal boundary layer near the heat transfer surface is found. The red layer at the right corner of the plane is clearly found to be thinner when augmented the $\mathrm{s} / \mathrm{H}$, while the red layer at the left corner slightly increases. The distribution of all color layers has change when changed the $\mathrm{s} / \mathrm{H}$ value. This is because the gap between channel wall and ISR, which induces the vortices, that helps a better fluid mixing. Considering at the right corner of the plane, the $\mathrm{s} / \mathrm{H}=0.30$ performs the lowest red layer thickness, while the $\mathrm{s} / \mathrm{H}=0$ provides the opposite behavior.

Figs. 7, 8, 9, 10, 11 and 12 present the local Nusselt number distributions on the channel walls of the heat exchanger equipped with ISR at $\mathrm{BR}=0.05,0.10,0.15,0.20,0.25$ and 0.30 , respectively. The channel wall number is presented as Fig. 6. In general, the present of the ISR in the heat exchanger channel can enhance heat transfer rate higher than the smooth channel in all investigated cases. The peak of heat transfer regime has change when changed the $\mathrm{s} / \mathrm{H}$ value.

For $\mathrm{BR}=0.05$, the maximum of heat transfer rate for $\mathrm{w}_{1}$ and $\mathrm{w}_{2}$ is found at $\mathrm{s} / \mathrm{H}=0.10$, while found at $\mathrm{s} / \mathrm{H}$ around $0.20-0.30$, when considered at $\mathrm{w}_{3}$ and $\mathrm{w}_{4}$.
At $\mathrm{BR}=0.10$, the $\mathrm{s} / \mathrm{H}=0$ performs the highest heat transfer rate at $\mathrm{w}_{1}$ and $\mathrm{w}_{2}$. The heat transfer rate at $\mathrm{w}_{3}$ and $\mathrm{w}_{4}$ increases when $\mathrm{s} / \mathrm{H}>0$. The heat transfer rate for $\mathrm{w}_{1}$ and $\mathrm{w}_{2}$ decreases when enhanced $\mathrm{s} / \mathrm{H}$ value.

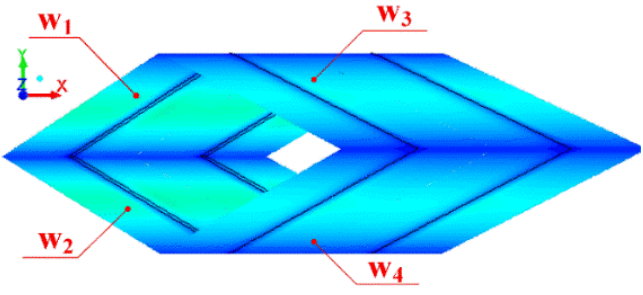

Fig. 6 Wall number.

Considering at $\mathrm{BR}=0.15$, it is seem that the $\mathrm{s} / \mathrm{H}=0$ gives the best heat transfer distributions at $\mathrm{w}_{1}$ and $\mathrm{w}_{2}$. The highest heat transfer rate at w3 and $\mathrm{w}_{4}$ is detected at $\mathrm{s} / \mathrm{H}$ around $0.20-0.30$.

The maximum Nusselt number is found at $\mathrm{s} / \mathrm{H}=0.30,0.25$ and 0.20 for $\mathrm{BR}=0.20,0.25$ and 0.30 , respectively, while the $\mathrm{s} / \mathrm{H}=0$ performs the reverse behavior.

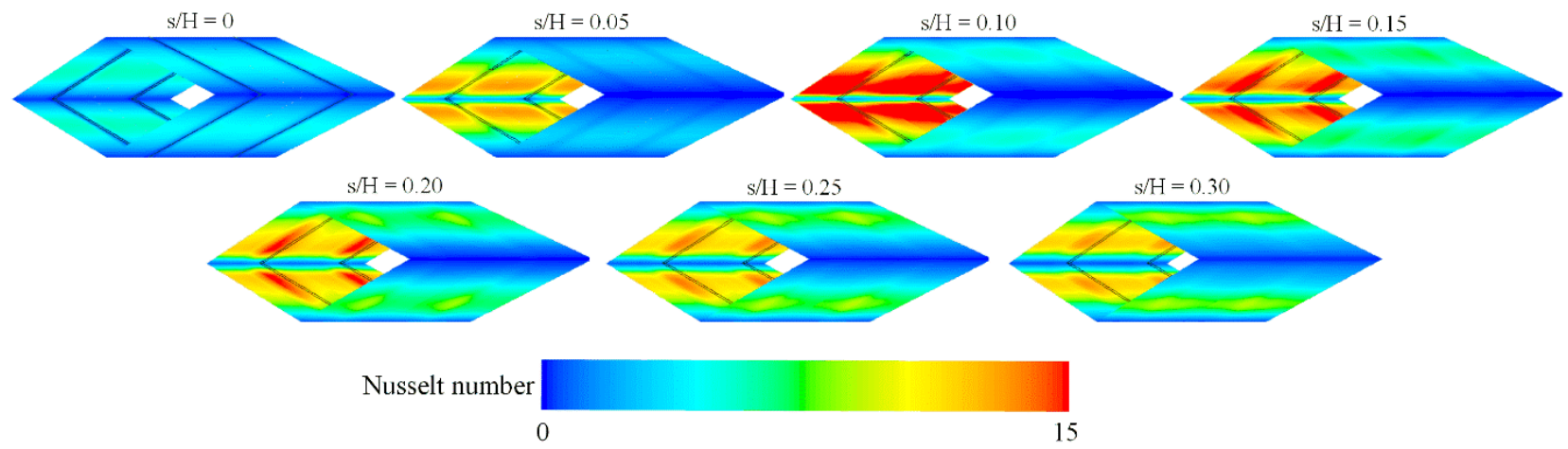

Fig. 7 Local Nusselt number distributions on the channel wall of the heat exchanger square channel inserted with ISR at BR $=0.05$.

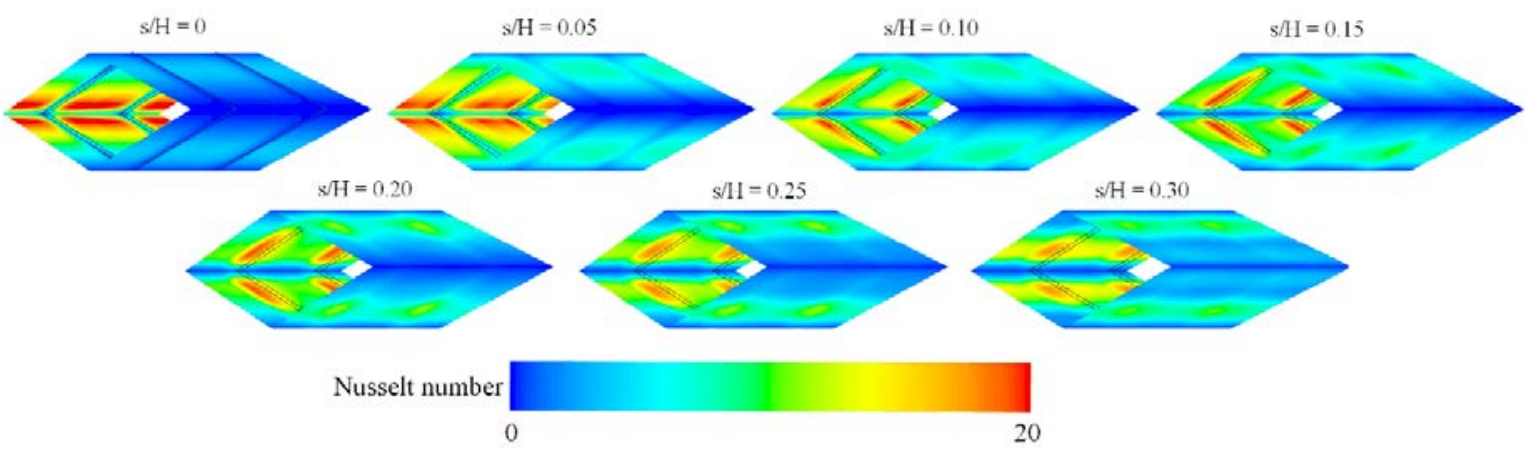

Fig. 8 Local Nusselt number distributions on the channel wall of the heat exchanger square channel inserted with ISR at BR $=0.10$.

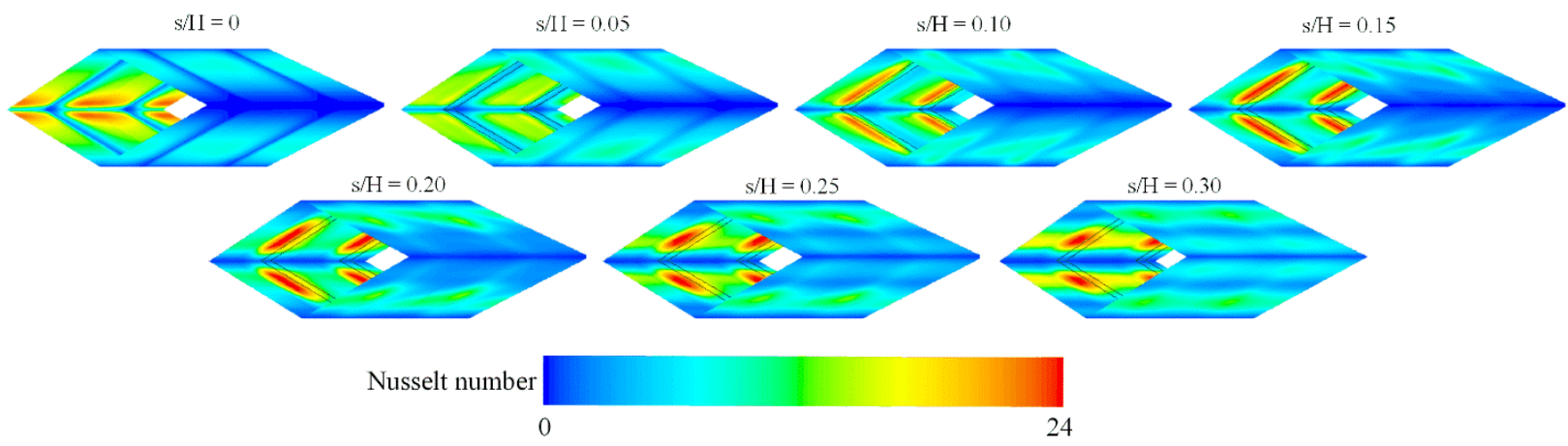

Fig. 9 Local Nusselt number distributions on the channel wall of the heat exchanger square channel inserted with ISR at BR $=0.15$. 

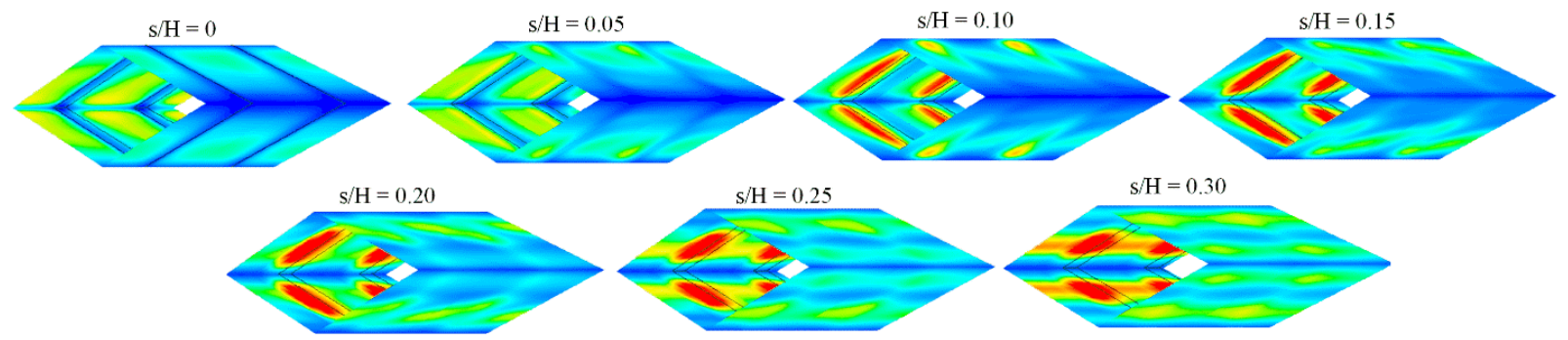

Nusselt number

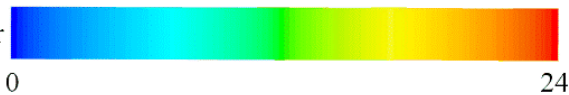

Fig. 10 Local Nusselt number distributions on the channel wall of the heat exchanger square channel inserted with ISR at BR $=0.20$.
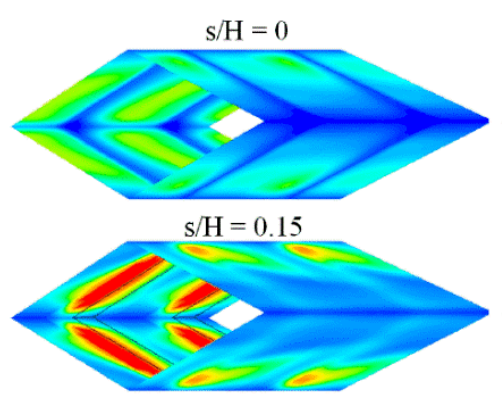

Nusselt number

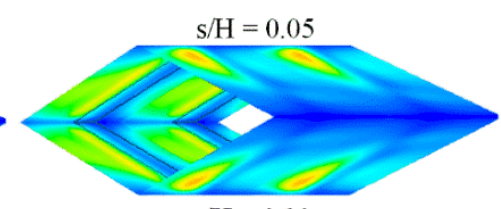

$\mathrm{s} / \mathrm{H}=0.20$

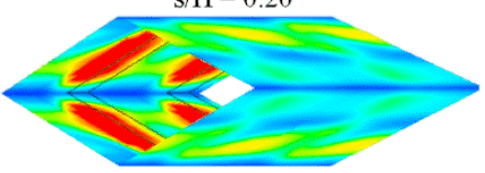

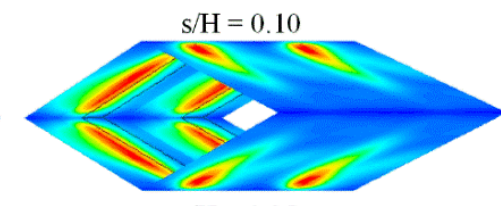

$\mathrm{s} / \mathrm{H}=0.25$

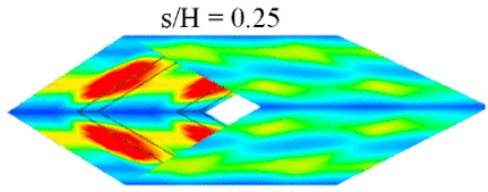

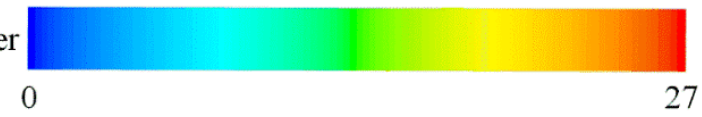

Fig. 11 Local Nusselt number distributions on the channel wall of the heat exchanger square channel inserted with ISR at BR $=0.25$.
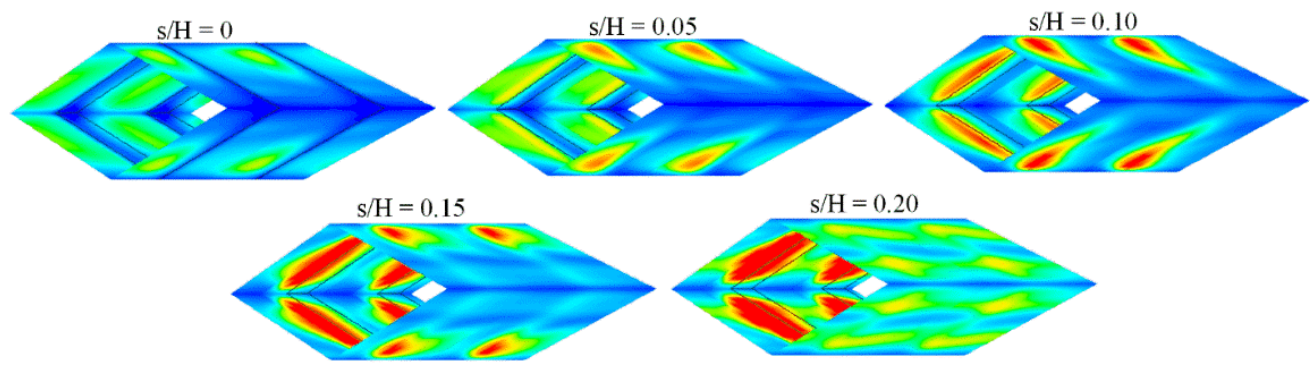

Nusselt number

0

30

Fig. 12 Local Nusselt number distributions on the channel wall of the heat exchanger square channel inserted with ISR at BR $=0.30$.

\subsection{Performance evaluation}

Figs. 13a, b, c, d, e and $\mathrm{f}$ report the relation of the $\mathrm{Nu} / \mathrm{Nu}_{0}$ with the Reynolds number at various $\mathrm{s} / \mathrm{H}$ for the heat exchanger square channel equipped with ISR of $\mathrm{BR}=0.05,0.10,0.15,0.20,0.25$ and 0.30, respectively. As the figures, the installation of the ISR in the heating section provides higher heat transfer coefficient than the smooth channel with no ISR in all studied cases. The Nusselt number ratio is higher than 1. In almost cases, the heat transfer rate increases when augmenting the Reynolds number. In the range studies, the Nusselt number is around $1.00-8.13$ times greater than the smooth square channel for $\mathrm{BR}=0.05$ $-0.30, \mathrm{Re}=100-2000$ and $\mathrm{s} / \mathrm{H}=0-0.30$.

Figs. 14a, b, c, d, e and $\mathrm{f}$ plot the variation of the $\mathrm{f} / \mathrm{f}_{0}$ with the Reynolds number with various $\mathrm{s} / \mathrm{H}$ for $\mathrm{BR}=0.05,0.10,0.15,0.20,0.25$ and 0.30 , respectively. The fitting of the ISR in the heating system brings the higher friction loss when compared with the smooth channel in all tested cases. The friction factor ratio is higher than the unity. The $f / f_{0}$ enhances when augmenting the Reynolds number. In the range investigates, the $\mathrm{f} / \mathrm{f}_{0}$ is found to be around $1.00-20.55$ for the ISR with $\mathrm{BR}=0.05-0.30, \mathrm{Re}=100-2000$ and $\mathrm{s} / \mathrm{H}=0-0.30$.
Figs. 15a, b, c, d, e and $\mathrm{f}$ depict the relation of the TEF and Re for the heat exchanger square channel equipped with ISR at $\mathrm{BR}=0.05,0.10$, $0.15,0.20,0.25$ and 0.30 , respectively. Due to the installation of the ISR in the tested section enhances both heat transfer rate and pressure loss, therefore, the thermal efficiency is selected to analyze the efficiency of the ISR. The thermal efficiency is reported in terms of thermal enhance factor or TEF, which considered at similar pumping power. Almost cases, the insertion of the ISR provides higher TEF than the smooth channel or TEF $>1$. The optimum TEF is around 2.10, 2.16, 1.98, 2.41, 3.09 and 2.97, respectively, for $\mathrm{BR}=0.05,0.10,015,0.20,0.25$ and 0.30 .

The peak of heat transfer rate in each Reynolds number is not found in similar $\mathrm{s} / \mathrm{H}$ value. Seeing at $\mathrm{BR}=0.05$, the $\mathrm{s} / \mathrm{H}=0.20$ gives the maximum heat transfer rate at $\mathrm{Re}=400$ and 600 , while the $\mathrm{s} / \mathrm{H}=0.10$ performs the highest heat transfer rate at $\mathrm{Re}=1000$ and 1200 . Considering at $\mathrm{Re}=2000$, the highest Nusselt number is detected at $\mathrm{s} / \mathrm{H}$ $=0.05,0,0.30,0.20,0.20$ and 0.20 for $\mathrm{BR}=0.05,0.10,0.15,0.20,0.25$ and 0.30 , respectively.

The friction loss tends to increase when augmenting the $\mathrm{s} / \mathrm{H}$ value for all BRs. The extreme increase of the friction factor is detected when $\mathrm{Re}>800$ and $\mathrm{BR}>0.10$. In addition, the installation of the ISR on the 
square channel wall $(\mathrm{s} / \mathrm{H}=0)$ can help to reduce the pressure loss when compared with the other positions. The maximum friction loss is found at $\mathrm{s} / \mathrm{H}=0.30$ for $\mathrm{BR}=0.05-0.20$, while found at $\mathrm{s} / \mathrm{H}=0.25$ and 0.20 for $\mathrm{BR}=0.25$ and 0.30 .

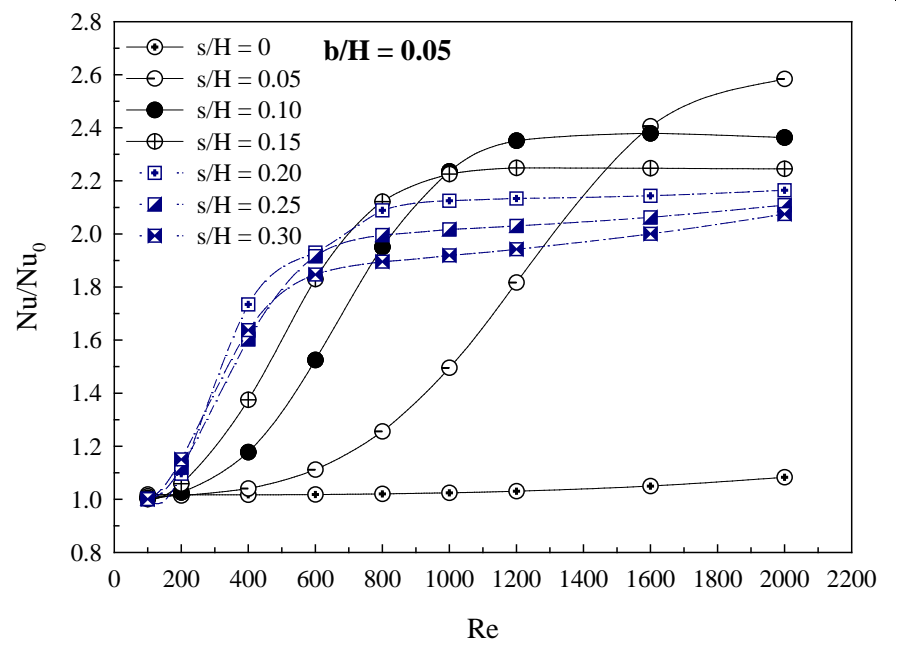

(a)

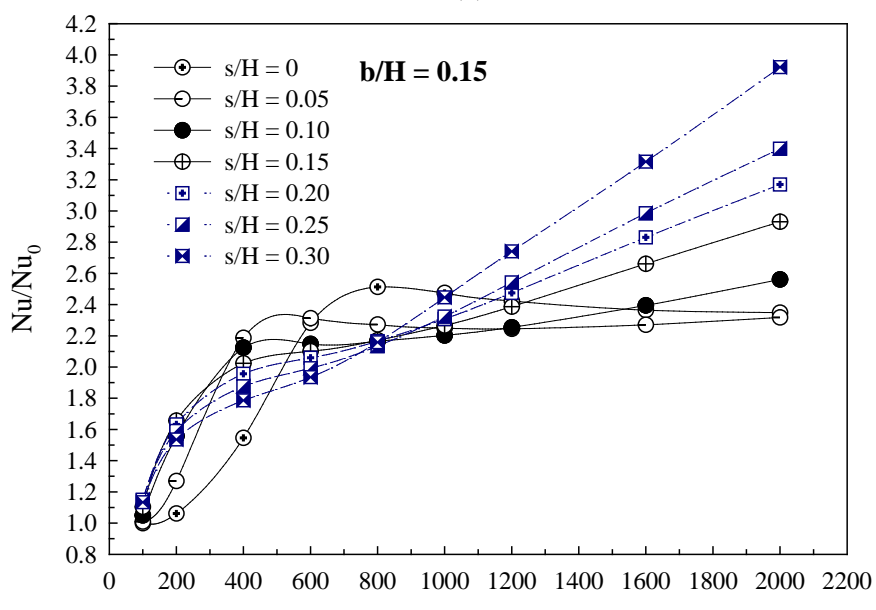

$\mathrm{Re}$

(c)

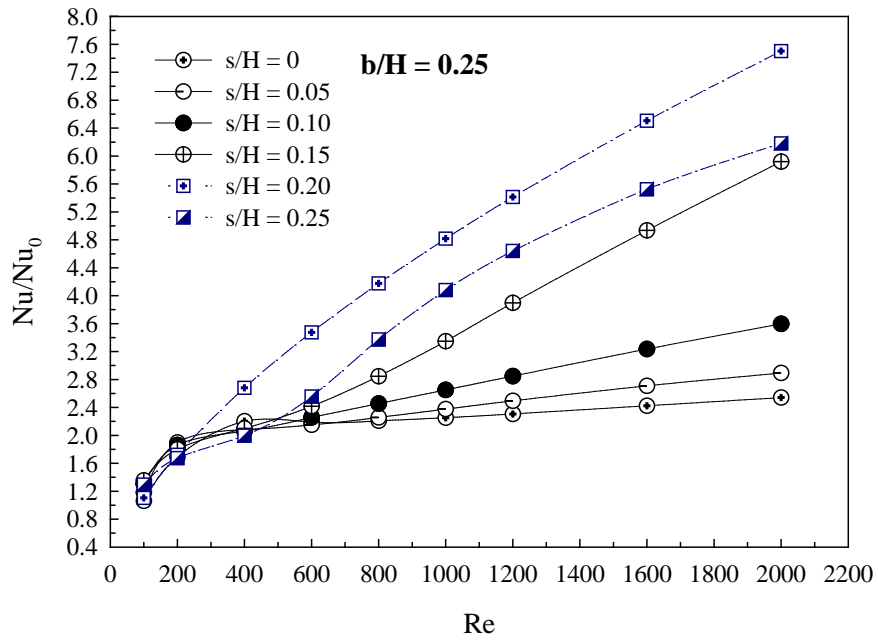

(e)
Considering at $\mathrm{Re}=2000$, the optimum TEF is detected at $\mathrm{s} / \mathrm{H}=$ $0.05,0$ and 0.30 for $\mathrm{BR}=0.05,0.10$ and 0.15 , respectively, while found at $\mathrm{s} / \mathrm{H}=0.20$ for $\mathrm{BR}>0.15$.

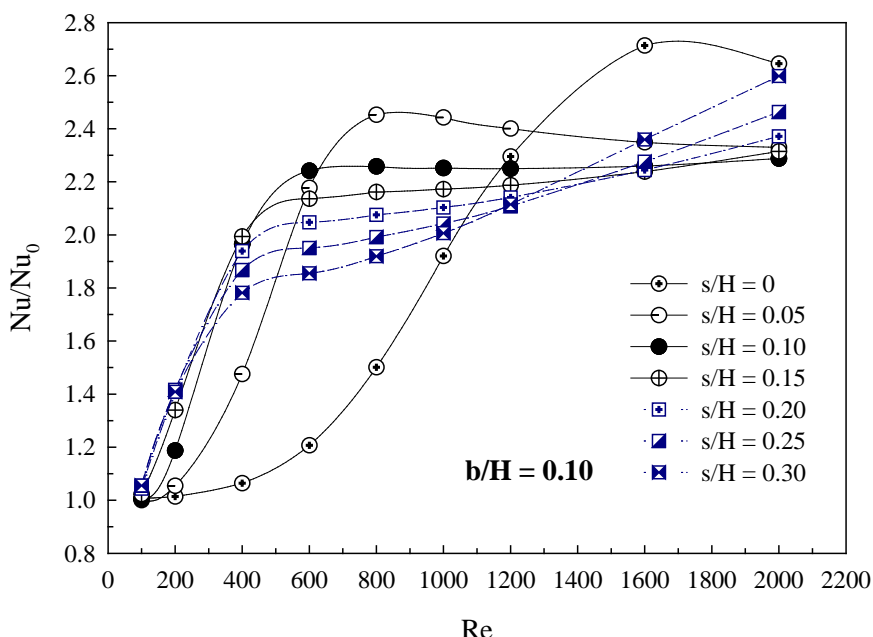

(b)

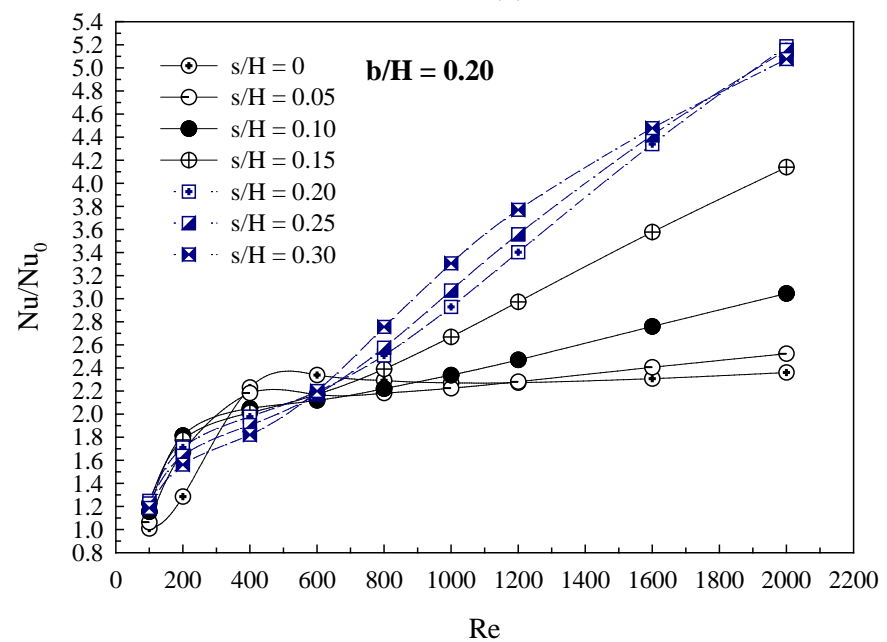

(d)

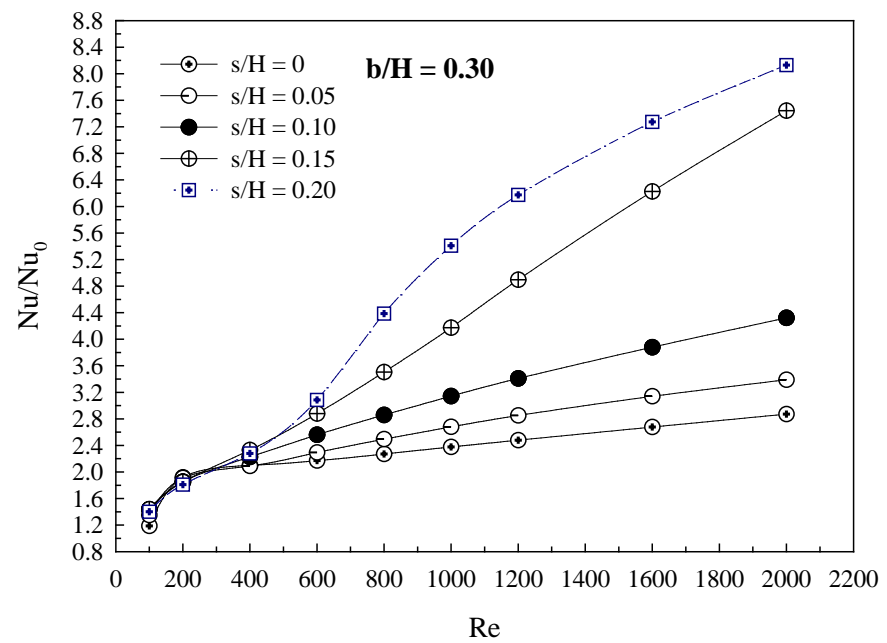

(f)

Fig. $13 \mathrm{Nu} / \mathrm{Nu}_{0}$ versus Re for the heat exchanger square channel inserted with ISR of (a) $\mathrm{BR}=0.05$, (b) $\mathrm{BR}=0.10,(\mathrm{c}) \mathrm{BR}=0.15$, (d) $\mathrm{BR}=0.20$, (e) $\mathrm{BR}=0.25$ and (f) $\mathrm{BR}=0.30$. 


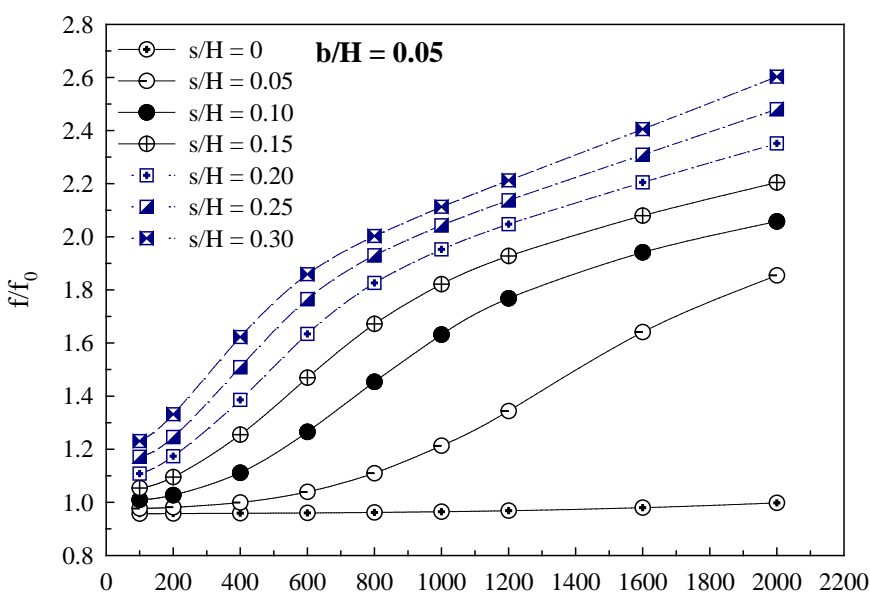

Re

(a)

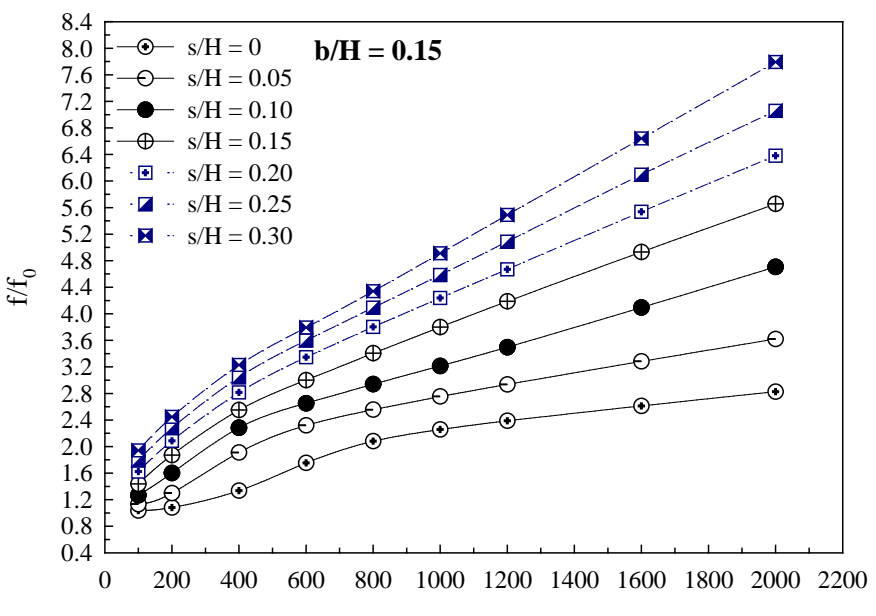

Re

(c)

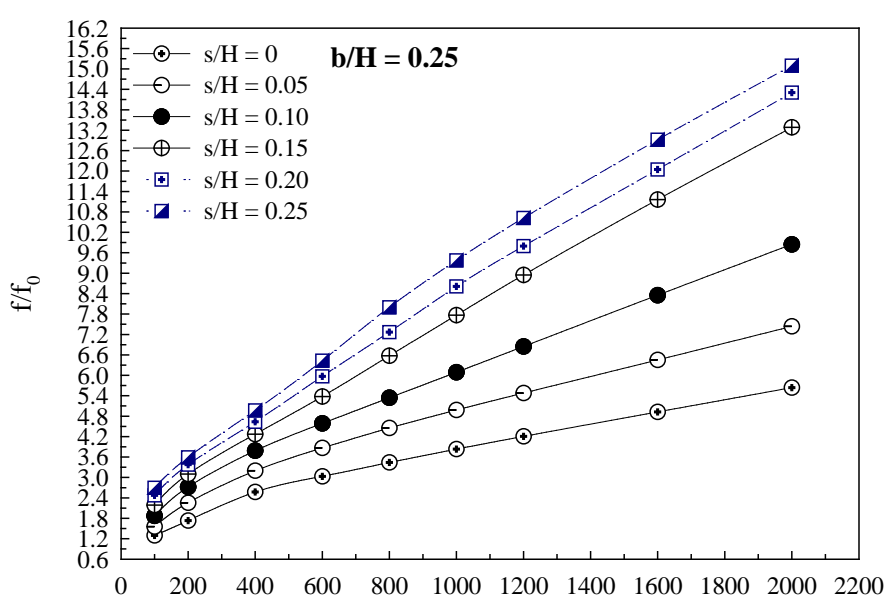

$\mathrm{Re}$

(e)

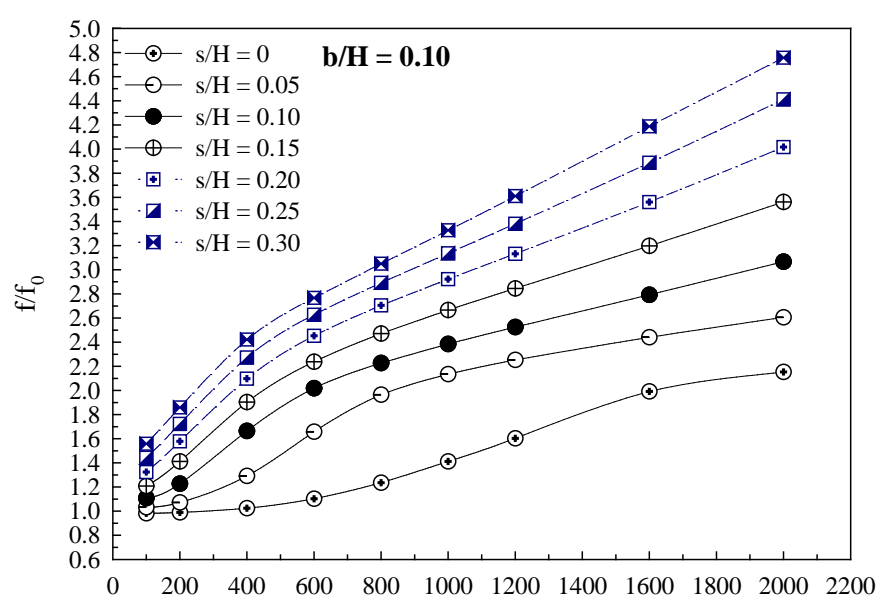

Re

(b)

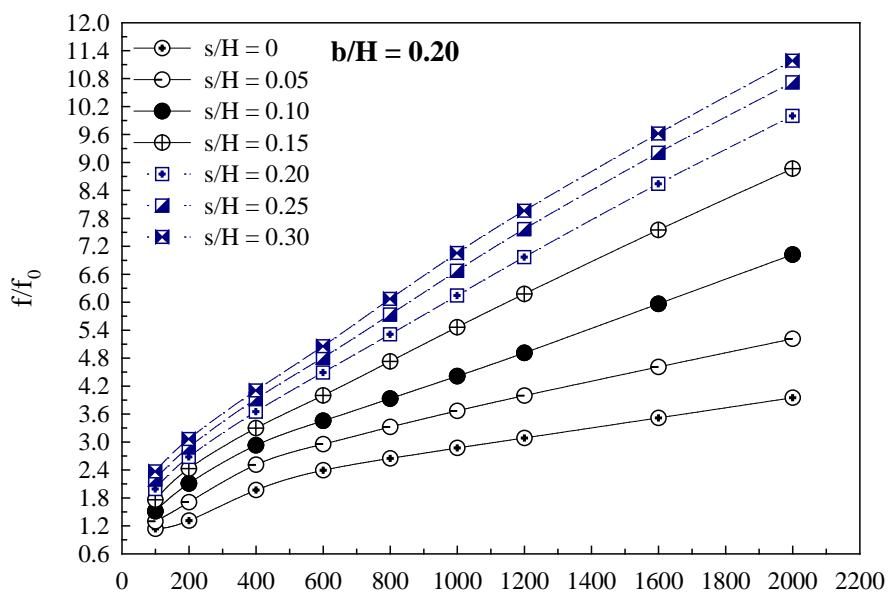

$\mathrm{Re}$

(d)

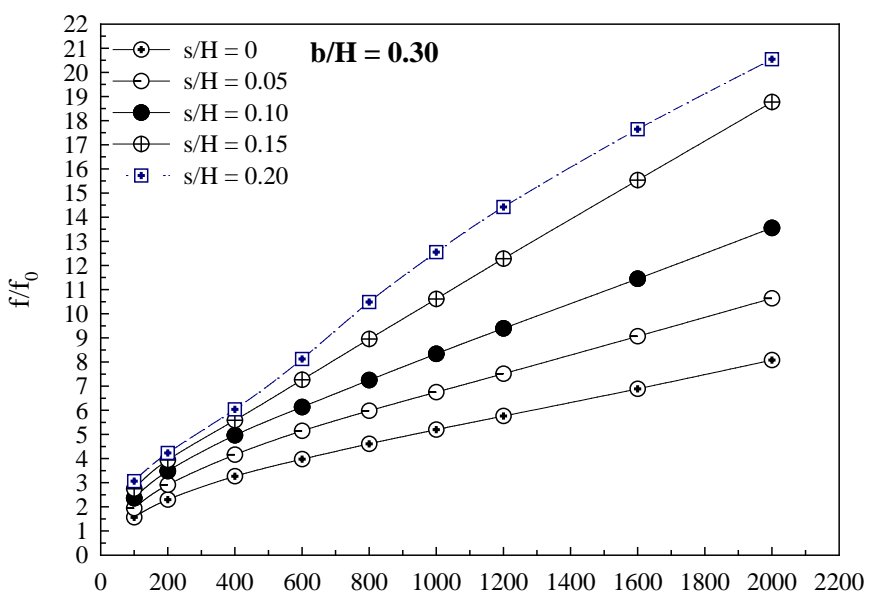

$\operatorname{Re}$

(f)

Fig. $14 \mathrm{f} / \mathrm{f}_{0}$ versus Re for the heat exchanger square channel inserted with ISR of (a) $B R=0.05$, (b) $B R=0.10$, (c) $B R=0.15$, (d) $B R=0.20$, (e) $B R$ $=0.25$ and $(\mathrm{f}) \mathrm{BR}=0.30$. 


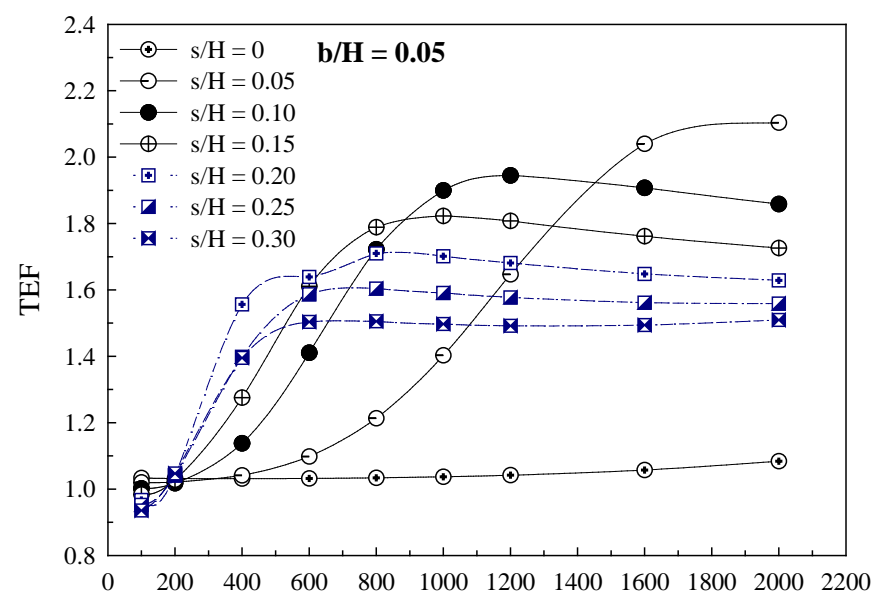

Re

(a)

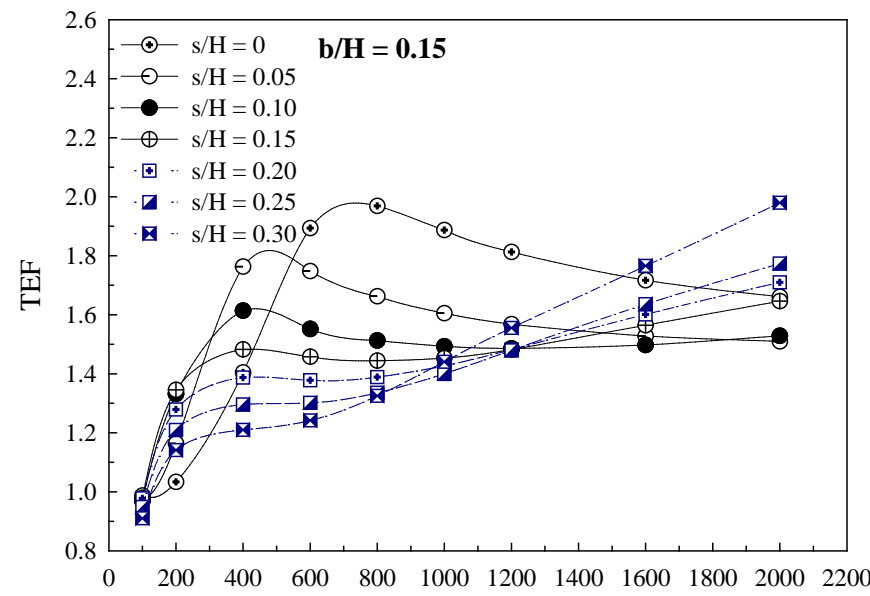

$\operatorname{Re}$

(c)

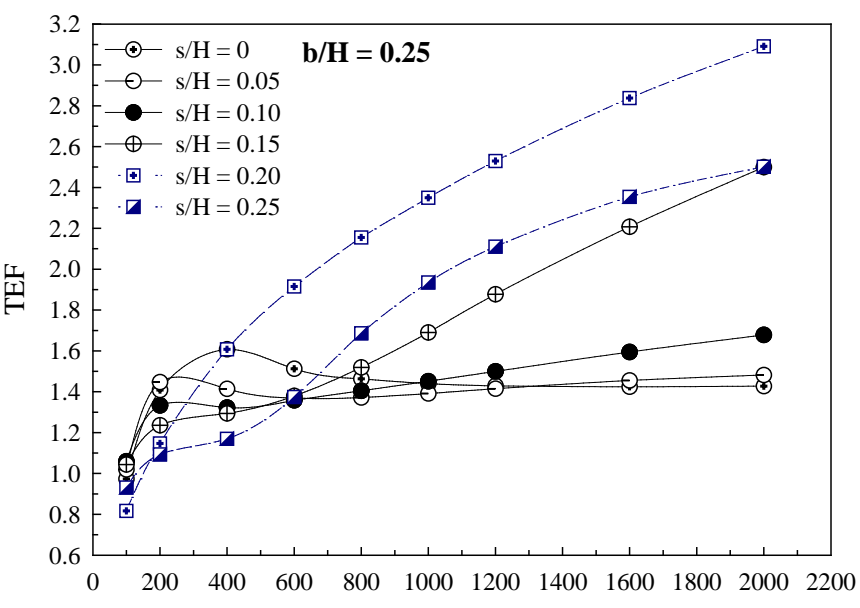

$\operatorname{Re}$

(e)

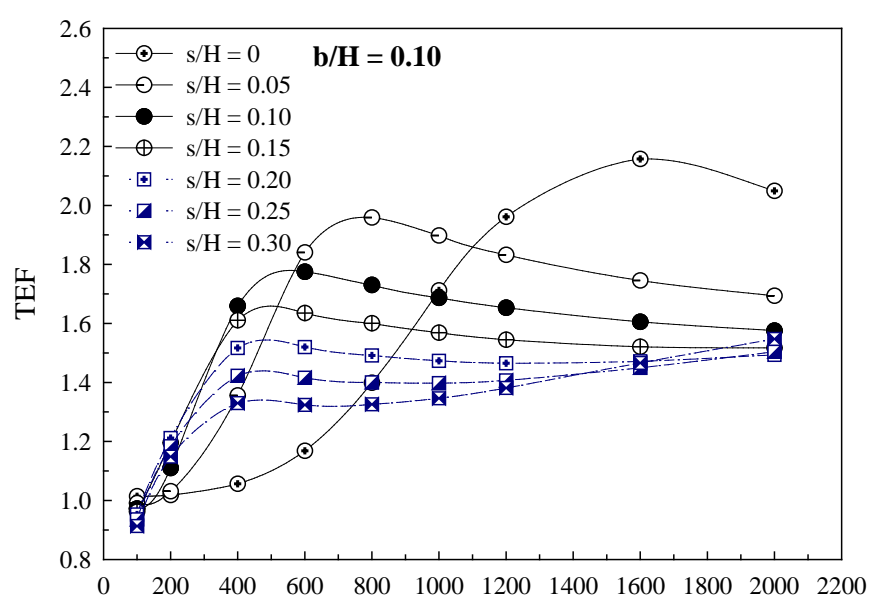

$\operatorname{Re}$

(b)

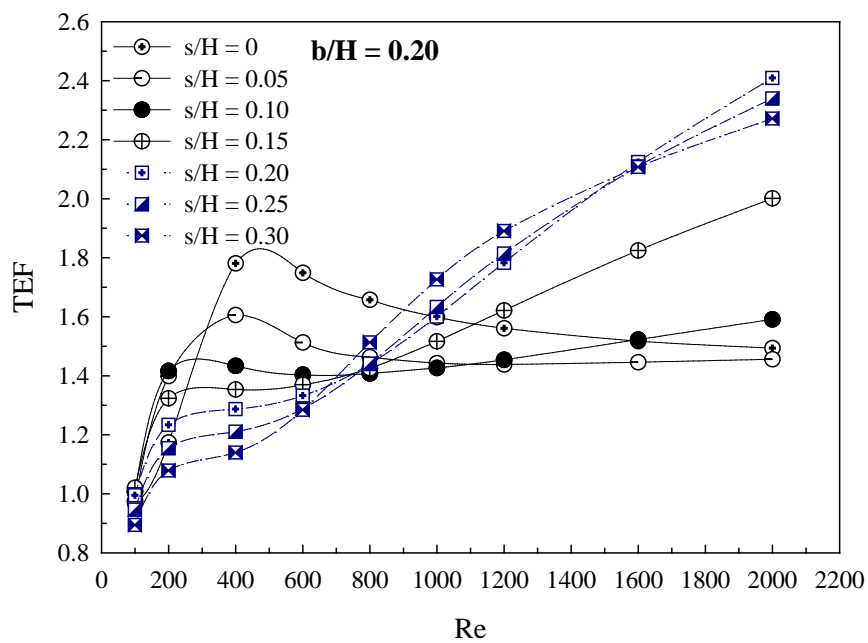

(d)

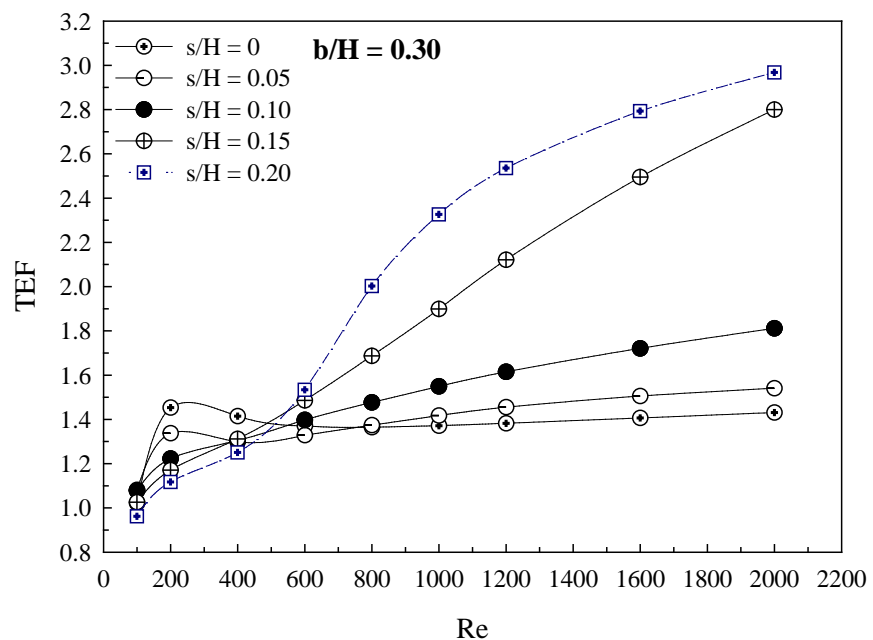

(f)

Fig. 15 TEF versus Re for the heat exchanger square channel inserted with ISR of (a) BR=0.05, (b) $B R=0.10$, (c) $B R=0.15$, (d) $B R=0.20$, (e) $\mathrm{BR}=0.25$ and (f) $\mathrm{BR}=0.30$. 


\section{CONCLUSION}

Numerical predictions on flow topology and heat transfer characteristic in the heat exchanger square channel equipped with $30^{\circ}$ ISR are reported for the present research. The influences of ISR size and position on mechanisms in the heating section are investigated. The laminar flow regime with the Reynolds number around $100-2000$ is considered. The outcomes of the present work can conclude as follows;

The generation of the vortex flow is found when installed ISR in the heat exchanger channel. The disturbance of the thermal boundary layer is also found in the present investigation. These behaviors are reasons for the augmentations of the heat transfer rate and thermal efficiency.

The size and position of the ISR have effect for the changes of heat transfer and flow behaviors. The small vortices near the channel walls are detected when $\mathrm{s} / \mathrm{H}>0$. The optimum $\mathrm{s} / \mathrm{H}$ value may give high heat transfer rate and thermal performance. For low BR, the suggestion of the $\mathrm{s} / \mathrm{H}$ is around $5-15 \%$, while around $20 \%$ when $\mathrm{BR}>0.20$.

In comparison, the stable of the installation for the present vortex generator are higher than the previous types (Promvonge et al. (2010), Jedsadaratanachai et al. (2011), Promvonge et al. (2012), Jedsadaratanachai and Boonloi (2014)), while the thermal performance of the present work is nearly as the previous works (Promvonge et al. (2010), Jedsadaratanachai et al. (2011), Promvonge et al. (2012), Jedsadaratanachai and Boonloi (2014)).

\section{ACKNOWLEDGEMENTS}

The authors would like to thank Assoc. Prof. Dr. Pongjet Promvonge for suggestions. This research was funded by King Mongkut's University of Technology North Bangkok, Contract no. KMUTNB-63-KNOW-010.

BR flow blockage ratio (=b/H)

\section{NOMENCLATURE}

b baffle height, $\mathrm{m}$

$\mathrm{D}_{\mathrm{h}}$ hydraulic diameter of channel, $\mathrm{m}$

f friction factor

$\mathrm{s}$ gap spacing, $\mathrm{m}$

$\mathrm{H}$ channel height, $\mathrm{m}$

$\mathrm{h}$ convective heat transfer coefficient, $\mathrm{W} \mathrm{m} \mathrm{m}^{-2} \mathrm{~K}^{-1}$

$\mathrm{k}$ thermal conductivity, $\mathrm{W} \mathrm{m} \mathrm{m}^{-1} \mathrm{~K}^{-1}$

$\mathrm{Nu}$ Nusselt number $(=\mathrm{hD} / \mathrm{k})$

$\mathrm{P}$ pitch spacing, $\mathrm{m}$

$\mathrm{PR}$ pitch ratio $(=\mathrm{P} / \mathrm{H})$

$\mathrm{P}$ static pressure, $\mathrm{Pa}$

Pr Prandtl number $(\mathrm{Pr}=0.707)$

Re Reynolds number

$\mathrm{T}$ temperature, $\mathrm{K}$

$\mathrm{u}_{\mathrm{i}} \quad$ velocity in $\mathrm{x}_{\mathrm{i}}$-direction, $\mathrm{m} \mathrm{s}^{-1}$

$\bar{u} \quad$ mean velocity in channel, $\mathrm{m} \mathrm{s}^{-1}$

Greek letter

TEF thermal enhancement factor $\left(=\left(\mathrm{Nu} / \mathrm{Nu}_{0}\right) /\left(\mathrm{f} / \mathrm{f}_{0}\right)^{1 / 3}\right)$

$\rho$ density, $\mathrm{kg} \mathrm{m}^{-3}$

Subscript

0 smooth tube

pp pumping power

\section{REFERENCE}

Ameur H., 2019, "Effect of the Baffle Inclination on the Flow and Thermal Fields in Channel Heat Exchangers”, Results in Engineering, 3, Article 100021.

https://doi.org/10.1016/j.rineng.2019.100021

Arani, A.A.A., and Moradi, R., 2019, "Shell and Tube Heat Exchanger Optimization using New Baffle and Tube Configuration," Applied Thermal Engineering, 157, Article 113736.

https://doi.org/10.1016/j.applthermaleng.2019.113736
Awais, M., and Bhuiyan, A.A., 2019, "Enhancement of Thermal and Hydraulic Performance of Compact Finned-tube Heat Exchanger using Vortex Generators (VGs): A Parametric Study”, International Journal of Thermal Sciences, 140, 154-166.

https://doi.org/10.1016/j.ijthermalsci.2019.02.041

Bahiraei, M., Mazaheri, N., Hosseini, Y., and Moayedi, H., 2019, “A Two-phase Simulation for Analyzing Thermohydraulic Performance of $\mathrm{Cu}$-water Nanofluid within a Square Channel Enhanced with $90^{\circ} \mathrm{V}$ Shaped Ribs”, International Journal of Heat and Mass Transfer, 145, Article 118612.

https://doi.org/10.1016/j.ijheatmasstransfer.2019.118612

Bai, W., Liang, D., Chen, W., and Chyu, M.K., 2019, "Investigation of Ribs Disturbed Entrance Effect of Heat Transfer and Pressure Drop in Pin-fin Array”, Applied Thermal Engineering, 162, Article 114214. https://doi.org/10.1016/j.applthermaleng.2019.114214

Cengel, Y.A., and Ghajar, A.J., 2015, "Heat and Mass Transfer: Fundamentals \& applications, Fifth edition in SI Units, McGraw-Hill Education, ISBN 978-981-4595-27-8

Dezan, D.J., Yanagihara, J.I., Jenovencio, G., and Salviano, L.O., 2019, "Parametric Investigation of Heat Transfer Enhancement and Pressure Loss in Louvered Fins with Longitudinal Vortex Generators", International Journal of Thermal Sciences, 135, 533-545. https://doi.org/10.1016/j.ijthermalsci.2018.09.039

Jedsadaratanachai, W., and Boonloi, A., 2014, "Effects of Blockage Ratio and Pitch Ratio on Thermal Performance in a Square Channel with $30^{\circ}$ Double V-baffles”, Case Studies in Thermal Engineering, 4, 118128.

https://doi.org/10.1016/j.csite.2014.08.002

Jedsadaratanachai, W., Suwannapan, S., and Promvonge, P., 2011, "Numerical Study of Laminar Heat Transfer in Baffled Square Channel with Various Pitches”, Energy Procedia, 9, 630-642.

https://doi.org/10.1016/j.egypro.2011.09.073

Li, Y., Rao, Y., Wang, D., Zhang, P., and Wu., X., 2019, “Heat Transfer and Pressure Loss of Turbulent Flow in Channels with Miniature Structured Ribs on One Wall”, International Journal of Heat and Mass Transfer, 131, 584-593.

https://doi.org/10.1016/j.ijheatmasstransfer.2018.11.067

Liu, P., Lv, J., Shan, F., Liu, Z., and Liu, W., 2019, "Effects of Rib Arrangements on the Performance of a Parabolic Trough Receiver with Ribbed Absorber Tube", Applied Thermal Engineering, 156, 1-13. https://doi.org/10.1016/j.applthermaleng.2019.04.037

Naqvi, S. M. A., Elfeky, K. E., Cao, Y., and Wang, Q., 2019, “Numerical Analysis on Performances of Shell Side in Segmental Baffles, Helical Baffles and Novel Clamping Anti-Vibration Baffles with Square Twisted Tubes Shell and Tube Heat Exchangers”, Energy Procedia, 158, 57705775.

https://doi.org/10.1016/j.egypro.2019.01.553

Patankar, S.V., Liu, C.H., and Sparrow, E.M., 1998, "Fully Developed Flow and Heat Transfer in Ducts having Streamwise-periodic Variations of Cross-sectional Area, ASME Journal of Heat Transfer, 98, 11091151.

https:// doi:10.1115/1.3450666

Promvonge, P., Jedsadaratanachai, W., Kwankaomeng, S., and Thianpong, C., 2012, “3D Simulation of Laminar Flow and Heat 
Transfer in V-baffled Square Channel”, International Communications in Heat and Mass Transfer, 39, 85-93.

https://doi.org/10.1016/j.icheatmasstransfer.2011.09.004

Promvonge, P., Jedsadaratanachai, W., and Kwankaomeng, S., 2010, "Numerical Study of Laminar Flow and Heat Transfer in Square Channel with $30^{\circ}$ Inline Angled Baffle Turbulators”, Applied Thermal Engineering, 30, 1292-1303.

https://doi.org/10.1016/j.applthermaleng.2010.02.014
Saravanakumar, T., and Kumar, D.S., 2019, "Performance Analysis on Heat Transfer Characteristics of Heat Sink with Baffles Attachment”, International Journal of Thermal Sciences, 142, 14-19.

https://doi.org/10.1016/j.ijthermalsci.2019.04.002

Zhai, C., Islam, M.D., Simmons, R., and Barsoum, I., 2019, "Heat Transfer Augmentation in a Circular Tube with Delta Winglet Vortex Generator Pairs”, International Journal of Thermal Sciences, 140, 480490.

https://doi.org/10.1016/j.ijthermalsci.2019.03.020 